\title{
Magnesium-Alloy for Orthopedic Application: Long Term Evaluation on Bone Compatibility and Degradation Under In Vivo Environment
}

\author{
Sau Shun Wong ${ }^{1}$, Luen Chow Chan², Chi Ping Lai*2, Wing Yuk Ip ${ }^{3}$ and Yuk Fai Lui ${ }^{1}$ \\ ${ }^{1}$ Department of Orthopaedics and Traumatology, PR China \\ ${ }^{2}$ Department of Industrial and Systems Engineering, PR China \\ ${ }^{3}$ Department of Orthopaedics and Traumatology, PR China \\ *Corresponding author: Chi Ping Lai, Department of Industrial and Systems Engineering, PR Hong Kong, China
}

\section{ARTICLE INFO}

Received: 豐 March 18, 2019

Published: 幽 March 27, 2019

\section{ABSTRACT}

Keywords: Magnesium-alloys; Degradation Behavior; In-vivo; Orthopedics application

Citation: Sau Shun Wong, Luen Chow Chan, Chi Ping Lai, Wing Yuk Ip, Yuk Fai Lui. Magnesium-Alloy for Orthopedic Application: Long Term Evaluation on Bone Compatibility and Degradation Under In Vivo Environment. Biomed J Sci \& Tech Res 16(3)-2019. BJSTR. MS.ID.002857.

\section{Introduction}

Bone resorption around stress-shielded area in bone fixation treatments is an important consideration within clinical sectors. To reduce the effect, a secondary surgery is usually required to remove the fixation devices after healing has completed Li [1]. This procedure may create additional surgical risks to the patient Beaupre et al. [2,3]. A biodegradable fixation device is a possible solution to counter this situation Li [1]. Among all the degradable biomaterials, magnesium alloy with its unique mechanical properties of metal has an advantage in fixation operation. Li [1,47] Magnesium and its alloys possess similar elastic modulus (41-45 $\mathrm{GPa}$ ) and density (1.72-1.84 $\mathrm{g} \mathrm{cm}^{-3}$ ) to that of bones (15-25 GPa; $1.8-2.1 \mathrm{~g} \mathrm{~cm}^{-3}$ ) Staiger et al. [8], making them more bone friendly than other metal-based alloys with higher density. Magnesium ion, the major degradation product, is tolerable by human body in considerable amount Trumbo et al. [9], with no toxic byproduct formed during the degradation process Li et al. [1,4,5]. Furthermore, magnesium implants have shown to stimulate new bone formation when used as bone fixture Witte et al. [10]. In this study, two magnesium-alloys with low and high zinc composition, namely LZnMg and HZnMg, were put under in-vivo evaluation inside the femur of S.D rats. Degradation rate and bone compatibility of the alloys were monitored online with micro CT within an 24 weeks duration [11-15].

\section{Results}

\section{Degradation Behavior}

The degradation process of the implant is visualized by 3D reconstruction images, as shown in Figure 1. The differences in the remaining volume and the degradation behaviors were already distinguishable at early stage (1 month) of the experiment. By week 4 there was an obvious volume loss in pure Mg implants [16-20]. The average volume was reduced by an average of $45 \%$ from its 
original volume $[21,22]$. In comparison, an average loss of only $4 \%$ is recorded in LZnMg implants while the structure remained almost unchanged except the formation of small and shallow pits on the surface [23-25]. For the $\mathrm{H}, \mathrm{Zn}, \mathrm{Mg}$ implants, over half of the implant volume was lost within 4 weeks and there was obvious change in implant dimensions. A sharp reduction in implant volume in week 16 was found in Mg group, while fragmentation of implant begins at week 6 in the H, Zn, Mg group. On the contrary, little dimension change could be detected inside LZnMg groups throughout the 24 weeks period. Degradation of LZnMg remained slow throughout the 24 weeks period. There was increasing amounts of small and shallow surface pits with an overall intact structure [26-30]. Overall, the degradation process in pure Mg implants was relatively uniform compared to $\mathrm{H}, \mathrm{Zn}, \mathrm{Mg}$ until the shape decreases in volume after week 12 . For $\mathrm{H}, \mathrm{Zn}, \mathrm{Mg}$, the implants generally disintegrate into small pieces by week 12 and completely degraded within 16 weeks.

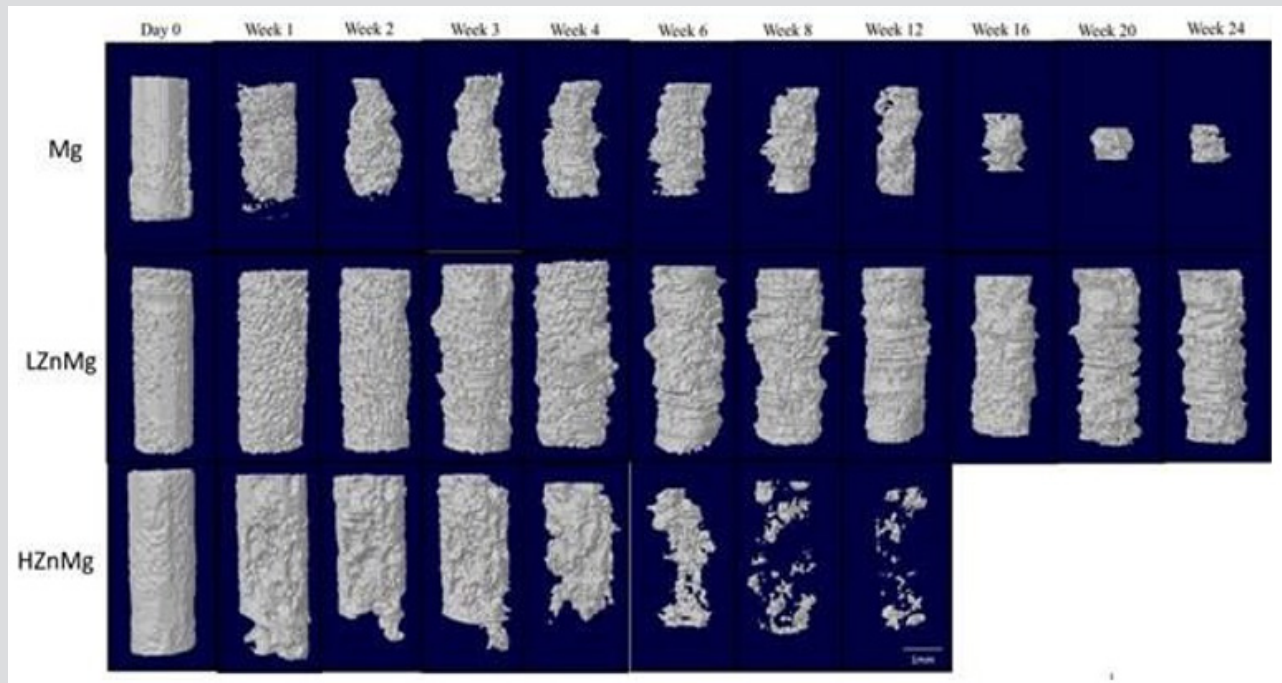

Figure 1: Micro-CT 3D reconstructions of the implants from day 0 to week 24.

\section{Surrounding Tissue Response}

Newly grown cortical bone could be found in all samples, as seen in Figure 2. Soft bone callus was found above the pure $\mathrm{Mg}$ and $\mathrm{H}, \mathrm{Zn}, \mathrm{Mg}$ implants. For the pure Mg group, bone callus appeared between week 3 and week 4, and a gap was observed between the cortical bone and the drill hole. These gaps, together with the drill holes, were eventually filled by the new cortical bone at later stage of healing (Figure 3). In the H, Zn, Mg group, bone callus was found between week 3 and week 8 [31-35]. The rate of new bone formation was not fast enough to cover the loss of implant volume. After complete degradation, the drill holes could still be observed until week 20. At the end of the experiment, there was an increase in thickness of the cortical bone. A small pit could sometimes be found on the surface of the femur. No callus formation could be observed with LZnMg implantation. Thin layers of new cortical bones were found around the implant instead.

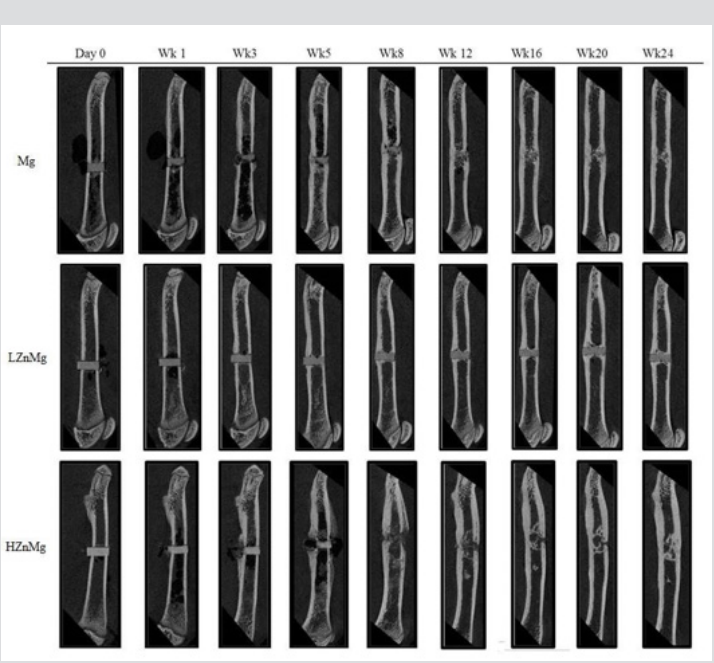

Figure 2: Micro-CT reconstructions 2D images showing the gas formation and the interaction between the implants and the bone growth at weeks 12, 16, 20, 24 . 


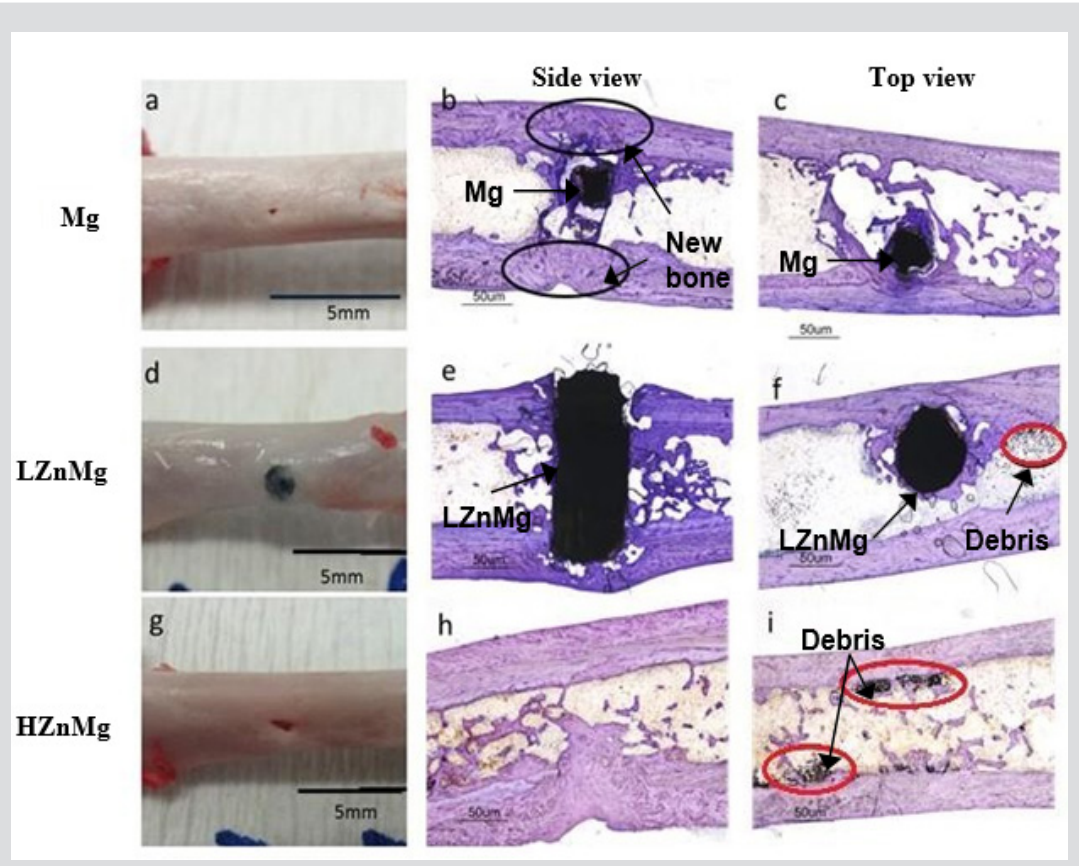

Figure 3: $(a, d, g)$ Images of the extracted femurs at the end of the experiment $(t=$ week 24$)$.

Calcified tissue could be found proliferating around the implant at around week 5 of the experiment, which was considerably earlier than other experimental groups [36,37]. Nevertheless, the degradation process was not completed, and the implants could still be found occupying the drill hole at week 24 . New bone growth is indicated by the light shallow area around the operation area. Gas capsule is seen around the implant indicated by the dark empty space. Histological staining indicated that there were close contact between bone and pure magnesium implant residues. New bones could grow around the implant material, as shown in Figure 3. Similar observation was found in samples with LZnMg implants, where new bones could grow around and make close contact with the implanted material. The drill hole was still occupied by the implant in this experimental group due to the much slower degradation rate [38-40].

In the experimental group implanted with $\mathrm{H}, \mathrm{Zn}, \mathrm{Mg}$, the implant completely degraded after 24 weeks. In both experimental groups with magnesium alloy implants, dark particles are found near the implant site under histological sections (Figure 3). The implant or the drill hole can still be seen clearly on the femurs of most samples. Toluidine Blue 0 staining of the cross-sections (side view: b, e, h; top view: c, f, i) of the implants and bones harvested at week 24 . Black circles in (b) indicate the filled gaps and drill holes by new cortical bone. Red circles in (f, i) indicate particles/debris located near the operation area in experimental groups implanted with magnesium-alloys [40-43].

\section{Conclusion}

Degradation process and bone compatibility of magnesium can be modified with $\mathrm{Zn} / \mathrm{Mn}$ alloying. The LZnMg alloy in this presented study can provide good structural integrity throughout a 24 weeks implantation in the femur of rat models. The alloy can also allow the formation of a close bone-implant interface, with new bone formation next to and around the implant. All these findings demonstrated the LZnMg alloy's potential as the basial material of an new orthopaedics fixation device. Evaluation on toxicity measurement and biomechanical properties during the degradation is suggested for further investigation.

\section{Acknowledgement}

The work described in this paper was partially supported by the Research Committee of the Hong Kong Polytechnic University (Project No. G-YBRL) and the Small Project Funding of the University of Hong Kong (Project No. 201309176011).

\section{References}

1. Li N, Zheng Y (2013) Novel magnesium alloys developed for biomedical application: a review. J Mater Sci Technol 29(6): 489-502.

2. Beaupre GS, Csongradi JJ (1996) Refracture risk after plate removal in the forearm. J Orthop Trauma 10(2): 87-92.

3. Krettek C, Muller C, Meller R, Jagodzinski M, Hildebrand F, et al. (2012) Is routine implant removal after trauma surgery sensible? Unfallchirurg 115(4): 315-322.

4. Kubasek J, Vojtech D (2013) Structural characteristics and corrosion behavior of biodegradable Mg- Zn, Mg-Zn-Gd alloys. J Mater Sci Mater Med 24(7): 1615-1626.

5. Bakhsjeshi Rad HR, Idris MH, Abdul Kadir MR, Farahany S (2012) Microstructure analysis and corrosion behavior of biodegradable $\mathrm{Mg}-\mathrm{Ca}$ implant alloys. Materials \& Design 33: 88-97.

6. Wan P, Tan L, Yang K (2016) Surface modification on biodegradable magnesium alloys as orthopedic implant materials to improve the bioadaptability: a review. J Mater Sci Technol 32(9): 827-834. 
7. Ullmann B, Reifenrath J, Dziuba D, Seitz J, Bormann D, et al. (2011) In vivo degradation behavior of the magnesium alloy LANd442 in rabbit tibiae. Materials 4(12): 2197-2218.

8. Staiger MP, Pietak AM, Huadmai J, Dias G (2006) Magnesium and its alloys as orthopedic biomaterials Magnesium and its alloys as orthopedic biomaterials: a review. Biomaterials 27(9): 1728-1734.

9. Trumbo P, Schlicker S, Yates AA, Poos M (2002) Dietary reference intakes for energy carbohydrate, fiber, fat, fatty acids, cholesterol, protein and amino acids. J Am Diet Assoc 102(11): 1621-1630.

10. Witte F, Fisher J, Nellesen J, Crostack HA, Kaese V, et al. (2006) In vitro and in vivo corrosion measurements of magnesium alloys. Biomaterials 27(7): 1013-1018.

11. Andrews EW (1917) Absorbable metal clips as substitutes for ligatures in wound closure. JAMA 28: 278-281.

12. Avedesian MM, Baker H (1999) ASM Speciality Handbook: Magnesium and Magnesium alloys. ASM International.

13. Chen Y, Xu Z, Smith C, Sanker J (2014) Recent advances on the development of magnesium alloys for biodegradable implants. Acta Biomater 10(11): 4561-4573.

14. Rosalbino F, De Negri S, Saccone A, Angelini E, Delfino S (2010) Biocorrosion characterization of Mg-Zn- X $(X=\mathrm{Ca}, \mathrm{Mn}, \mathrm{Si})$ alloys for biomedical applications. J Mater Sci Mater Med 21(4): 1091-1098.

15. Zhang E, Yin D, Xu L, Yang L, Yang K (2009) Microstructure, mechanical and corrosion properties and biocompatibility of $\mathrm{Mg}-\mathrm{Zn}-\mathrm{Mn}$ alloys for biomedical application. Mater Sci Eng C 29(3): 987-993.

16. Fischerauer SF, Kraus T, Wu X, Tangl S, Sorantin E, et al. (2013) In vivo degradation performance of micro-arc-oxidized magnesium implants: A micro-CT study in rats. Acta Biomater 9(2): 5411-5420.

17. Gallagher JC, Sai AJ (2010) Molecular biology of bone remodeling: implications for new therapeutic targets for osteoporosis. Maturitas 65(4): 301-307.

18. Ghali E (2010) Corrosion resistance of aluminum and magnesium alloys: Understanding, performance, and Testing. John Wiley \& Sons, Inc USA.

19. Gu X, Zheng Y, Cheng Y, Shengping Zhong, Tingfei Xi (2009) In vitro corrosion and biocompatibility of binary magnesium alloys. Biomaterials 30(4): 484-498.

20. Hermawan H, Dube D, Mantovani D (2010) Developments in metallic biodegradable stents. Acta Biomaterialia 6(5): 1693-1697.

21. Huehnerschulte TA, Reifenrath J, Rechenberg B von, Dziuba D, Seitz JM, et al. (2012) In vivo assessment of the host reactions to the biodegradation of the two novel magnesium alloys ZEK100 and AX30 in an animal model. Biomed Eng Online 11: 14.

22. Huse EC (1878) A new ligature? Chicago Med J Exam 172: 2.

23. Lucey TD, Venugopal B (1977) Introduction to Heavy Metal Toxicity in Mammals. Plenum Press, USA pp. 1-37.

24. Moravej M, Mantovani D (2011) Biodegradable metals for cardiovascular stent application: Interests and new opportunities. Int J Mol Sci 12(7): $4250-4270$.

25. Peters CL, Hines JL, Bachus KN, Craig MA, Bloebaum RD (2006) Biological effects of calcium sulfate as a bone graft substitute in ovine metaphyseal defects. J Biomed Mater Res A 76(3): 456-462.
26. Rosalbino F, De Negri S, Scavino G, Saccone A (2013) Microstructure and in vitro degradation performance of $\mathrm{Mg}-\mathrm{Zn}-\mathrm{Mn}$ alloys for biomedical application. J Biomed Mater Res A 101(3): 704-711.

27. Seeling MG (1924) A study of magnesium wire as an absorbable suture and ligature material. Arch Surg 8 (2): 669-680.

28. Song GL, Atrens A (1999) Corrosion mechanism of magnesium alloys. Adv Eng Mater 1(1): 11-23.

29. Song G (2007) Control of biodegradation of biocompatible magnesium alloys. Corros Sci 49 (4): 1696-1701.

30. Song S, Song GL, Shen W, Liu M (2012) Corrosion and electrochemical evaluation of coated magnesium alloys. Corrosion 68 (1).

31. Tapiero H, Tew KD (2003) Trace elements in human physiology and pathology: zinc and metallothioneins. Biomed Pharmacother 57(9): 399-411.

32. Walker J, Shadanbaz S, Woodfield TB, Staiger MP, Dias GJ (2014) Magnesium biomaterials for orthopedic application: a review from a biological perspective. J Biomed Mater Res B Appl Biomater 102(6): 1316-1331.

33. Witecka A, Yamamoto A, Idaszek J, Chlanda A, Swieszkowski W (2016) Influence of biodegradable polymer coatings on corrosion, cytocompatibility and cell functionality of Mg-2.0Zn-0.98Mn magnesium alloy. Colloids Surf B Biointerfaces 144: 284-292.

34. Witte F, Hort N, Vogt C, Cohen S, Kainer KU, et al. (2008) Degradable biomaterials based on magnesium corrosion. Curr Opin Solid State Mater Sci 12(5-6): 63-72.

35. Witte F, Kaese V, Haferkamp H, Switzer E, Meyer Lindenberg A, et al. (2005) In vivo corrosion of four magnesium alloys and the associated bone response. Biomaterials 26(17): 3557-3563.

36. Xu L, Yu G, Zhang E, Pan F, Yang K (2007) In vivo corrosion behavior of Mg-Mn-Zn alloy for bone implant application. J Biomed Mater Res A 83(3): 703-711.

37. Xue D, Yun Y, Tan Z, Dong Z, Schulz MJ (2012) In vivo and in vitro degradation behavior of magnesium alloys as biomaterials. J Mater Sci Technol 28(3): 261-267.

38. Yin DS, Zhang EL, Zeng SY (2008) Effect of Zn on mechanical property and corrosion property of extruded Mg-Zn-Mn alloy. T Nonferr Metal Soc China 18(4): 763-768.

39.Zberg B, Uggowitzer PJ, Loffler JF (2009) MgZnCa glasses without clinically observable hydrogen evolution for biodegradable implants. Nat Mater 8: 88-891.

40. Zhang E, Chen H, Shen F (2010) Biocorrosion properties and blood and cell compatibility of pure iron as a biodegradable biomaterial. J Mater Sci Mater Med 21(7): 2151-2163.

41. Zhang S, Zhang X, Zhao C, Li J, Song Y, et al. (2010) Research on an Mg-Zn alloy as a degradable biomaterial. Acta Biomater 6(2): 626-640.

42. Zhao Y, Wu G, Jiang J, Wong HM, Yeung KWK, et al. (2012) Improved corrosion resistance and cytocompatibility of magnesium alloy by twostage cooling in thermal treatment. Corros Sci 59: 360-365.

43.Zheng YF, Gu X, Witte F (2014) Biodegradable metals. Mater Sci Eng R Rep 77: 1-34. 
ISSN: 2574-1241

DOI: 10.26717/BJSTR.2019.16.002857

Chi Ping Lai. Biomed J Sci \& Tech Res

(c) (P) This work is licensed under Creative

Submission Link: https://biomedres.us/submit-manuscript.php

\begin{tabular}{ll} 
BIOMEDICAL & \multicolumn{1}{c}{ Assets of Publishing with us } \\
RESEARCHES & - Global archiving of articles \\
- Immediate, unrestricted online access \\
- Rigorous Peer Review Process
\end{tabular}

